\title{
Manajemen Tehnik Pembelajaran Pendidikan Anak Usia Dini di Kawasan Pesisir Laut Kabupaten Gorontalo Utara
}

\author{
Arfan Utiarahman $^{\varpi_{1}}$, Novianty Djafri², Syamsu Q Badu ${ }^{3}$ \\ Tehnik Sipil Universitas Negeri Gorontalo ${ }_{1}$ \\ Manajemen Pendidikan, Universitas Negeri Gorontalo 2 \\ Pendidikan Matematika Universitas Negeri Gorontalo ${ }^{3}$ \\ DOI: $\underline{10.31004 / \text { obsesi.v4i2.497 }}$
}

\begin{abstract}
Abstrak
Pendidikan Anak Usia Dini penting untuk diolah dalam tehnik, tahap dan langkah serta strategi manajemen pembelajaran. Adapun tujuan penelitian ini adalah: untuk mendapatkan Model Manajemen Tehnik Pembelajaran Pendidikan Anak Usia Dini Dikawasan Pesisir Laut Tomilito Kabupaten Gorontalo Utara. Metode Penelitian ini menggunakan jenis penelitian fenomena masyarakat dengan pendekatan deskriptif kualitatif. Adapun tehnik pengumpulan data: observasi, wawancara dan angket, dengan tehnik analisis pengolahan data; pengumpulan data, reduksi data, penyajian data dan penarikan kesimpulan dan verifikasi. Hasil penelitian ini mendapatkan model pembelajaran interaktif dan sistem pembelajaran kooperatif, dengan indikator Manajemen Tehnik Pembelajaran Pendidikan Anak Usia Dini di Kawasan Pesisir pantai adalah: 1) Perencanaan pembelajaran yang berpusat pada anak dikawasan pesisir. 2) Mengorganisir pembelajaran yang aktif dikawasan pesisir. 3) Menggerakkan pendidikan anak usia dini, melalui pengalaman langsung dengan objek dikawasan pesisir 4) mengawasi pembelajaran PAUD mempertimbangkan keseluruhan aspek pengembangan, bermakna, manarik, dan fungsional dikawasan pesisir.

Kata Kunci: manajemen; pembelajaran; pendidikan anak usia dini
\end{abstract}

\begin{abstract}
Early Childhood Education is important to be processed in techniques, stages and steps and learning management strategies. The purpose of this study is: to obtain a Management Model for Early Childhood Education Learning Techniques in the Tomilito Coastal Area of North Gorontalo District. This research method uses a type of community phenomenon research with a qualitative descriptive approach. The data collection techniques: observation, interviews and questionnaires, with data processing analysis techniques; data collection, data reduction, data presentation and conclusion drawing and verification. The results of this study obtain interactive learning models and cooperative learning systems, with indicators of Management of Early Childhood Education Learning Techniques in Coastal Areas are: 1) Planning for child-centered learning in coastal areas. 2) Organizing active learning in the coastal area. 3) Mobilize early childhood education, through direct experience with objects in coastal areas 4) supervise PAUD learning considering all aspects of development, meaningful, interesting, and functional in coastal areas.
\end{abstract}

Keywords: management; learning; early childhood education

Copyright (c) 2020 Arfan Utiarahman, Novianty Djafri, Syamsu Q Badu

$\triangle$ Corresponding author:

Email Address : arfanutiarahman@ung.ac.id (Gorontalo, Indonesia)

Received 6 March 2020, Accepted 9 March 2020, Published 10 March 2020 


\section{PENDAHULUAN}

Kondisi geografis Indonesia sebagai negara yang terdiri dari lautan, kepulauan dan pantau memiliki pengaruh pada laju perkembangan masyarakat dalam segala aspek seperti perkembangan pada aspek ekonomi yang saat ini masih menjalani proses pemerataan yang tentunya pemerintah memiliki peran penting dalam hal tersebut sehingga munculnya otonomi daerah. Selain itu, aspek sosial kemasyarakatan dan tak luput juga adalah aspek pendidikan yang tentunya akan menentukan masa depan bangsa dan negara (Tanto et al., 2019). Berkaitan dengan kondisi geografis negara Indonesia yang dipisahkan oleh lautan pulau, maka hal tersebut merupakan salah satu kendala bagi pemerintah untuk dapat melaksanakan program-program yang dirancang khususnya pada bidang pemerataan pendidikan di Indonesia. Masyarakat yang memiliki bermacam-macam kultur serta perbedaan status sosial ekonomi juga akan mempengaruhi laju aspek pendidikan tersebut (Garzia et al., 2019; Hartman et al., 2017).

Masyarakat pesisir pantai disebut juga masyarakat marginal yang hidup di ujung daratan sebuah daerah atau wilayah. Kampung Desa Pesisir Laut Tomilito yang berbatasan dengan Atinggola dan ponelo kepulauan adalah salah satu lokasi pemukiman masyarakat di Kecamatan Kwandang Kabupaten Gorontalo Utara, di Provinsi Gorontalo atau dengan kata lain masyarakat Tomilito adalah penduduk di kecamatan anggreka yang bermukim di ujung utara Kabupaten Gorontalo Utara. Sebagai wilayah pesisir, Tomilito menjadi sebuah lokasi yang memiliki keunikan tersendiri. Hal tersebut dilihat dari masyarakatnya yang notabene adalah nelayan berangsur-angsur mengalami perubahan profesi menjadi peternak binatang, unggas, ikan hasil laut dan tambak, karena seiring dengan perolehan mendapatkan pendidikan edukasi untuk masyarakat, keluarga dan anak (Kasim et al., 2017).

Masyarakat Pesisir terdiri dari, masyarakat usia tua, dewasa, remaja dan muda, dengan tingkatan masyarakat yang produktif dan non produktif, sedangkan untuk jenjang pendidikan adalah, TK/PAUD, SD, SMP dan SMA. Masyarakat yang muda, masyarakat yang non produktif dan jenjang pendidikan yang menjadi keharusan untuk mendapatkan perhatian seriusan adalah untuk pendidikan anak usia dini. Pendidikan anak usia Dini merupakan suatu pembinaan yang memberikan stimulasi pada pertumbuhan dan perkembangan anak dari usia 0-6 tahun, dengan tujuan agar anak memiliki kesiapan dalam pendidikan selanjutnya (Ayuni \& Setiawati, 2019; Fakhrudin, 2010; Ita, 2018). Melalui usia ini dapat dengan mudah mengarahkan pribadinya mengembangkan kognitif (pengetahuan kemampuan dalam berbahasa, pemahaman, dan cara penerapannya), Aspek afektif (kemauan menerima, kemauan menanggapi, berkeyakinan, mengorganisasikan, dan pembentukan watak/karakteristik), aspek psikomotorik (keterampilan dasar), serta juga menumbuhkan rasa kepercayaan, keimanan, dan ketaqwaan kepada Tuhan Yang Maha Esa. Disamping itu pula, bahwa pendidikan anak usia dini memiliki jenjang pendidikan dalam proses pembelajarannya (Elya, 2020; Hägglund \& Samuelsson, 2009; Watini, 2019).

Masyarakat pesisir adalah sekelompok warga yang tinggal di wilayah pesisir yang hidup bersama dan memenuhi kebutuhan hidupnya dari sumber daya di wilayah pesisir. Masyarakat yang hidup di kota-kota atau permukiman pesisir memiliki karakteristik secara sosial ekonomis sangat terkait dengan sumber perekonomian dari wilayah laut (Prianto, 2005). Biasanya masyarakat yang tinggal di pesisir, kurang aware dengan pendidikan, masyarakat tersebut menganggap bahwa melaut adalah tujuan utama mereka. Hal ini sejalan dengan Masri Amiruddin (2017) bagi orang tua dikawasan pesisir Donggala anak dijadikan sebagai tumpuhan untuk membantu mendapatkan nafkah untuk memenuhi kebutuhan sehari-hari. Orang tua kurang memberikan perhatian terhadap pendidikan anak di sekolah, sehingga anak-anak tersebut jarang masuk sekolah justru membantu mencari ikan dan berlayar. Rahman \& Yusuf (2012) bahwa orang tua yang tinggal di pesisir atau nelayan tidak memiliki perencanaan yang amatang dalam pendidikan anak, karena orang tua memandang bahwa pendidikan menjadikan hal yang kurang penting sehingga anak 
adalah aset membantu pekerjaan orangtua di rumah atau membantu mencari nafkah dengan pergi melaut.

Adapun hasil observasi untuk masyarakat yang dikawasan pesisir untuk aktivitas anak yang berusia kurang lebih 5 tahun, banyak mendapatkan perlakuan psikologis yang harus dapat membantu pekerjaan dari orang tua, dalam bersama bertanggung jawab memenuhi kebutuhan ekonomi keluarga. Anak yang seharusnya mendapatkan pendidikan di pagi hari di sekolah, justru mengikuti orang tuanya pergi kelaut untuk menangkap ikan, menjual disekitar laut dan lainnya. Untuk itu, yang menjadi faktor utama pada penelitian ini adalah tentang bagaimana Manajemen Tehnik Pembelajaran Pendidikan Anak Usia Dini Dikawasan Pesisir Laut Tomilito Kabupaten Gorontalo Utara Provinsi Gorontalo.

Pendidikan Anak Usia Dini penting untuk dimenej dalam tehnik, tahap dan langkah serta strategi manajemen pembelajaran. Manajemen adalah proses perencanaan, pengorganisasian, pengarahan, dan pengawasan usaha-usaha para anggota dan penggunaan sumber daya-sumber daya organisasi lainnya agar mencapai tujuan organisasi yang telah ditetapkan bersama (Çalışkan \& Özdemir, 2018; Fatimah \& Rohmah, 2016; Kadir \& Adebayo, 2019; Munastiwi, 2019; Patimah \& Nurhayati, 2020; Rohmat, 2017). Tehnik adalah suatu struktur konseptual yang tersusun dari fungsi-fungsi yang saling berhubungan yang bekerja sebagai suatu kesatuan organik untuk mencapai suatu hasil yang diinginkan (John Mc, 2010). Adapun menurut Barnawi \& Adi (2011) bahwa pembelajaran yang berorientasi pada anak usia dini yang disesuaikan dengan tingkat usia anak, artinya pembelajaran harus diminati, kemampuan yang diharapkan dapat dicapai, serta kegiatan belajar dapat menantang peserta didik untuk dilakukan sesuai usia anak.

Dalam menejemen tehnik pembelajaran anak usia dini hendaknya memiliki strategi pembelajaran yang ada di PAUD. Strategi pembelajaran sangat penting untuk dilakukan, untuk mendorong semangat belajar anak dalam proses pembelajaran yang dapat mengembangkan potensi anak sehigga tercapainya tujuan pembelajaran dengan baik (Nuraeni, 2014; Saripudin \& Faujiah, 2018). Stratgei pembelajaran pada anak usia dini yaitu Strategi Pembelajaran yang Berpusat pada Anak. Pendekatan yang melandasi pembelajaran yang berpusat pada anak. Anak merupakan individu yang sedang tumbuh dan berkembang. Anak juga merupakan makhluk yang aktif. Atas dasar fakta tersebut maka dikembangkan strategi pembelajaran berdasarkan: 1) pendekatan perkembangan dan 2) pendekatan belajar aktif. Karakteristik pembelajaran yang berpusat pada anak. Pembelajaran yang berpusat pada anak memiliki karakteristik sebagai berikut (Masitoh \& dkk, 2005). Prakarsa kegiatan tumbuh dari anak. 1) Anak memilih bahan-bahan dan memutuskan apa yang akan dikerjakan. 2) Anak mengekspresikan bahan-bahan secara aktif dengan seluruh inderanya. 3) Anak menemukan sebab akibat melalui pengalaman langsung dengan objek. 4) Anak mentransformasi dan menggabungkan bahan-bahan. 5) Anak menggunakan otot kasarnya. Karakteristik Pembelajaran Anak Usia Dini Komponen pembelajaran memiliki karakteristik atau ciri-ciri khusus. Menurut (Barnawi \& Adi, 2011), pembelajaran anak usia dini memiliki karakteristik sebagai berikut: 1) anak belajar melalui bermain, 2) anak belajar dengan cara membangun pengetahuannya, 3) anak belajar secara ilmiah, 4) anak belajar paling baik jika apa yang dipelajarinya mempertimbangkan keseluruhan aspek pengembangan, bermakna, manarik, dan fungsional.

Berdasarkan pengertian diatas maka indikator Manajemen Tehnik Pembelajaran Pendidikan Anak Usia Dini di Kawasan Pesisir Laut adalah: 1) Perencanaan pembelajaran yang berpusat pada anak dikawasan pesisir. 2) Mengorganisir pembelajaran yang aktif dikawasan pesisir. 3) Menggerakkan pendidikan anak usia dini, melalui pengalaman langsung dengan objek dikawasan pesisir 4) mengawasi pembelajaran PAUD mempertimbangkan keseluruhan aspek pengembangan, bermakna, manarik, dan fungsional dikawasan pesisir. 
Keterbaruan dari penelitian ini adalah mendapatkan model manajemen tehnik pembelajaran pendidikan anak usia dini yang ada dikawasan pesisir laut khususnya di Kabupaten Gorontalo Utara yang meliputi: Perencanaan pembelajaran yang berpusat pada anak dikawasan pesisir, Mengorganisir pembelajaran yang aktif dikawasan pesisir, Menggerakkan pendidikan anak usia dini, mengawasi pembelajaran PAUD mempertimbangkan keseluruhan aspek pengembangan. Tujuan dilakukan penelitian ini yaitu untuk mendapatkan model manajemen tehnik pembelajaran pendidikan anak usia dini dikawasan pesisir laut Tomilito Kabupaten Gorontalo Utara Provinsi Gorontalo. Sedangkan penelitian sebelumnya oleh Ita (2018) mendeskripsikan manajemen pembelajaran pendidikan anak usia dini di TK Rutosuro yaitu perencanaan pembelajaran, pelaksanaan pembelajaran, dan penilaian pembelajaran.

\section{METODOLOGI}

Jenis penelitian ini adalah penelitian deskriptif kualitatif yang mendeskripsikan manajemen tehnik pembelajaran PAUD Mutiara Pantai di Tomilito pesisir pantai Anggrek, di Kabupaten Gorontalo Utara. Penelitian kualitatif dinarasikan tidak berdasarkan angkaangka numerik. Penelitian ini disajikan secara deskriptif melalui fenomena dan kedaaan yang sebenarnya suapaya jelas. Penelitian kualitatif menghindari penyederhanaan fenomena yang ada untuk mengungkap perilaku dan pemahaman sebagai hasil dari interaksi. Penelitian kualitatif ini didasarkan pada asumsi bahwa interaksi sosial yang terjadi dalam pendidikan anak usia dini merupakan hal yang komplek, dan peneliti mengungkap kekomplekan tersebut. Pemilihan pendekatan penelitian ini didasarkan atas pertimbangan bahwa data yang hendak diungkap adalah data yang menggambarkan peran seseorang secara menyeluruh, tidak hanya dalam hitungan angka. Disamping itu pendekatan ini juga bertujuan untuk memperoleh pemahaman dan penafsiran secara mendalam tentang makna dari fenomena yang ada pada pelaksanaan Manajemen Pembelajaran PAUD Mutiara Pantai di Anggrek Gorontalo Utara. Analisis terhadap data yang terkumpul berkaitan dengan penelitian tentang manajemen pembelajaran PAUD Mutiara Pantai di Anggrek Gorontalo Utara dengan analisis deskriptif kualitatif melalui model pembelajaran interaktif yang dikembangkan Miles \& Huberman (2005). Analisis data dalam model ini terdiri atas empat komponen yang saling berinteraksi, yaitu pengumpulan data (observasi, wawancara dan angket), reduksi data, penyajian data dan penarikan kesimpulan dan verifikasi.

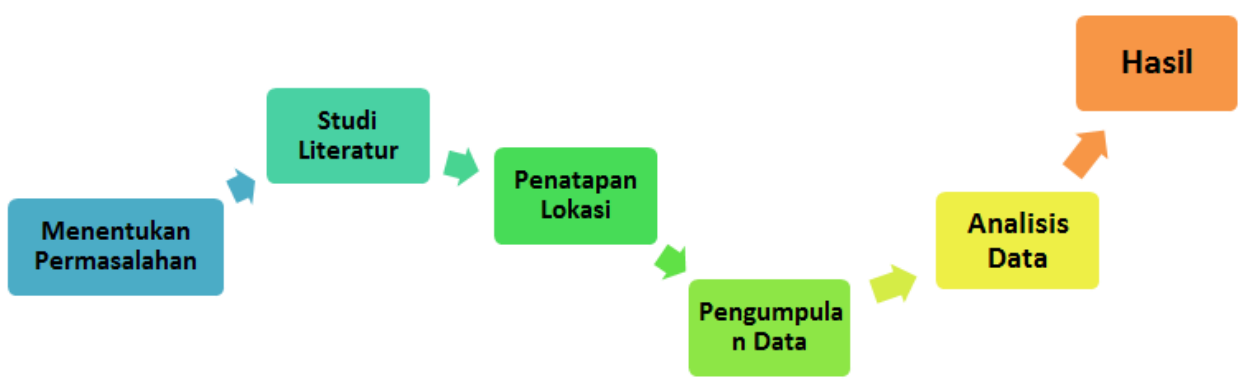

Gambar 1. Tahapan Penelitian Kualitatif (Suryana, 2007)

\section{HASIL DAN PEMBAHASAN}

Strategi Komponen-Komponen Pembelajaran PAUD Mutiara Laut di Tomilito Pesisir Pantai Anggrek, di Kabupaten Gorontalo Utara. Setiap komponen pembelajaran memiliki karakteristik atau ciri-ciri khusus. Komponen pembelajaran Pembelajaran PAUD Mutiara 
Pantai di Tomilito Pesisir Pantai Anggrek, di Kabupaten Gorontalo Utara dapat dilihat pada gambar berikut:

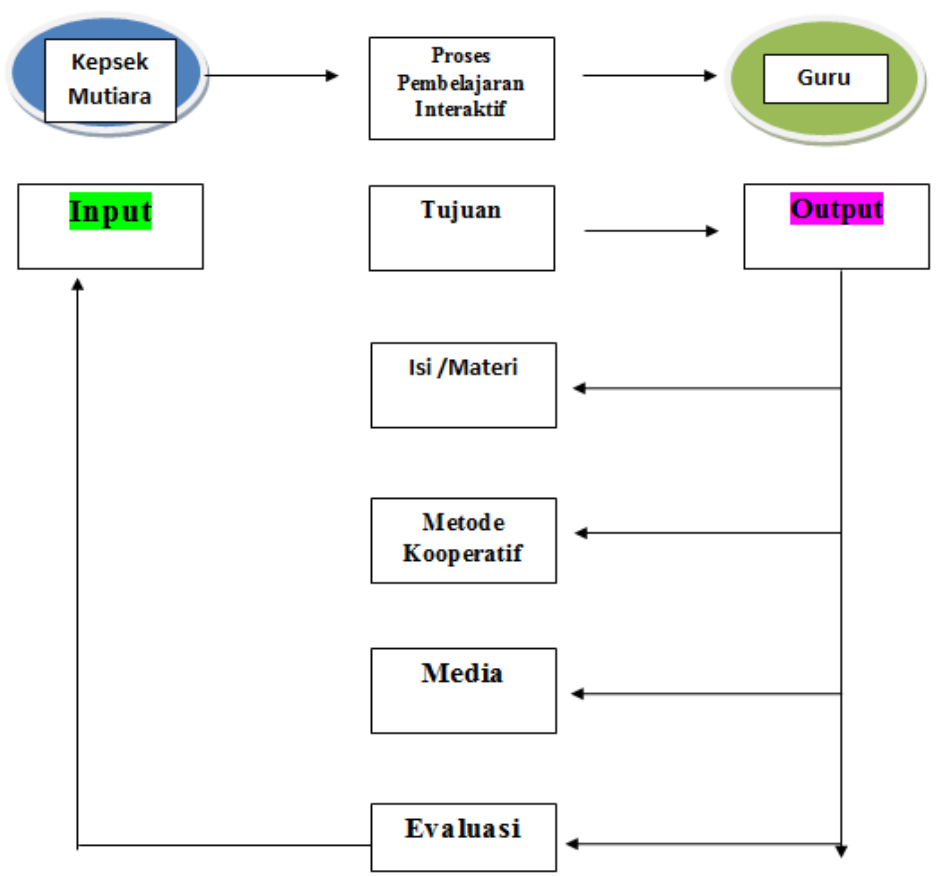

\section{Gambar 2. Strategi Komponen-Komponen Pembelajaran PAUD Mutiara Laut di Tomilito Pesisir Pantai Anggrek, di Kabupaten Gorontalo Utara}

Berdasarkan hasil penelitian bahwa Manajemen Tehnik Pembelajaran PAUD Mutiara Laut di Tomilito Pesisir Pantai Anggrek, di Kabupaten Gorontalo Utara menggunakan model pembelajaran interaktif, yakni model pembelajaran yang terus mengkonfirmasikan dengan orang tua atau perwalian anak, agar setiap anak terus mendapatkan pendidikan yang layak dan baik, juga menjalankan sistem pembelajaran kooperatif, yang dalam ini pihak sekolah selalu bekerjasama dengan orang tua untuk dapat memberikan pelayanan pendidikan kepada anak usia dini.

Tabel 1. Hasil Strategi Peluang untuk Model Pembelajaran Interaktif di kawasan Pesisir

\begin{tabular}{|l|l|c|c|c|c|l|l|l|}
\hline No & $\begin{array}{l}\text { Faktor-faktor } \\
\text { Strategis }\end{array}$ & \multicolumn{2}{|c|}{ Bobot Nilai 0-5 } & $\begin{array}{l}\text { Bobot x } \\
\text { Nilai }\end{array}$ & \multicolumn{1}{c|}{ Keterangan } \\
\cline { 3 - 8 } & Ortu & Guru & Masy & Kriteria & \multicolumn{1}{c|}{ Ortu } & \multicolumn{1}{|c|}{ Guru } & Pemerintah/Masy \\
\hline 1 & $\begin{array}{l}\text { Perencanaan } \\
\text { pembelajaran }\end{array}$ & 3 & 5 & 0 & Sedang & $\begin{array}{l}\text { Ortu harus lebih } \\
\text { dapat } \\
\text { merencanakan } \\
\text { pembelajaran } \\
\text { untuk anaknya }\end{array}$ & $\begin{array}{l}\text { Peran Guru } \\
\text { optimal dalam } \\
\text { perencenaan }\end{array}$ & $\begin{array}{l}\text { Pemerintah harus } \\
\text { dapat mengedukasi } \\
\text { masyarakat untuk } \\
\text { pentingnya } \\
\text { perencanaan } \\
\text { pendidikan }\end{array}$ \\
\hline 2 & $\begin{array}{l}\text { Mengorganisir } \\
\text { pembelajaran }\end{array}$ & 5 & 5 & 1 & Baik & $\begin{array}{l}\text { Ortu yang aktif } \\
\text { dalam } \\
\text { mengorganisir } \\
\text { pembelajaran }\end{array}$ & $\begin{array}{l}\text { Guru dapat } \\
\text { mengorganisir } \\
\text { siswa/wi, ortu } \\
\text { dan } \\
\text { masyarakat }\end{array}$ & $\begin{array}{l}\text { Pemerintah } \\
\text { menyerahkan } \\
\text { sepenuhnya organisir } \\
\text { pembelajran kepada } \\
\text { warga sekolah }\end{array}$ \\
\hline 3 & $\begin{array}{l}\text { Menggerakka } \\
\text { pendidikan } \\
\text { anak usia dini }\end{array}$ & 1 & 5 & 0 & Rendah & $\begin{array}{l}\text { Ortu belum } \\
\text { optimal } \\
\text { menggerakkan } \\
\text { anaknya }\end{array}$ & $\begin{array}{l}\text { Guru aktif } \\
\text { memotivasi } \\
\text { anak-anak }\end{array}$ & $\begin{array}{l}\text { Stimulus pemerintah } \\
\text { rendah dalam } \\
\text { menggerakkan anak } \\
\text { dan guru. }\end{array}$ \\
\hline 4 & $\begin{array}{l}\text { Mengawasi } \\
\text { pembelajaran } \\
\text { PAUD }\end{array}$ & 4 & 5 & 1 & Sedang & $\begin{array}{l}\text { Ortu teru dapat } \\
\text { berkontribusi } \\
\text { untuk kemajuan } \\
\text { pendidikan } \\
\text { anak-anak }\end{array}$ & $\begin{array}{l}\text { Guru dapat } \\
\text { menjadi } \\
\text { mediasi untuk } \\
\text { ortu dan } \\
\text { pemerintah }\end{array}$ & $\begin{array}{l}\text { Pemerintah dan } \\
\text { masyarakat dapat } \\
\text { menjadi pengawas } \\
\text { untuk kualitas } \\
\text { sekolah. }\end{array}$ \\
\hline
\end{tabular}

Sumber: data diolah 2019 
Pada perencanaan pembelajaran yang berpusat pada anak dikawasan pesisir, mendapatkan respon guru yang tinggi, namun belum sepenuhya di dukung oleh motivasi orang tua dan belum mendapatkan dukungan pemerintah setempat, karena kondisi Pendidikan Anak usia dini dikawasan pesisir di PAUD Mutiara Laut, di Tomilito Pesisir Pantai Anggrek, di Kabupaten Gorontalo Utara, sangat memprihatinkan. Beberapa anak usia dini tertinggal dalam menuntut ilmu, antara lain diakibatkan oleh letak sekolah yang agak jauh dari pemukiman warga, sehingga melewati pesisir pantai membuat anak tidak bersemangat untuk mendatangi sekolah. Wilayah pemukiman masyarakat yang terletak dipesisir pantai, sehingga anak-anak, yang diusia awal mendapatkan pondasi keilmuan, tidak termotivasi karena keadaan keluarga yang harus memenuhi perekomian keluarga, sehingganya anak-anak pesisir ikut dilibatkan orang tua mencari nafkah untuk menopang pemenuhan kebutuhan hidup sehari-hari dan akhirnya mengabaikan pendidikan.

Mengorganisir pembelajaran yang aktif dikawasan pesisir, akan lebih baik jika mendapatkan respon positif dari guru dan orang tua, namun rendah jika tidak di dukung oleh respon pemerintah dan masyarakat. Dari hasil penelitian terkadang banyak fasilitas yng kurang oleh sarana pembelajaran PAUD Kondisi pendidikan anak-anak di kawasan pesisir di PAUD Mutiara Laut, di Tomilito Pesisir Pantai Anggrek, di Kabupaten Gorontalo Utara yang sangat memprihatinkan. Beberapa data hasil lapangan bahwa sekolah PAUD dari segi fasilitasnya bermasalah, sehingga kesempatan anak PAUD di wilayah pesisir masih tertinggal dalam menuntut ilmu, antara lain sarana dasar pendidikan yang minim, dan keterbatasan wawasan tentang pentingnya pendidikan di kalangan orang tua.

Menggerakkan pendidikan anak usia dini, melalui pengalaman langsung dengan objek dikawasan pesisir; dari hasil penelitian peran orang tua sangat penting. Namun, belum maskimal karena ada disetiap orang tua memiliki tingkat perekonomian yang berbeda, makanya dalam memotivasi anaknya sekolah nilainya rendah, diakibatkan respon ornagtua yang tingkat pendapatan dan kesejahteraannya rendah. Dari hasil wawancara dengan pemerintah kelurahan, respon masyarakat bahwa bidang fenomena sosial pemukiman yang kumuh sampai ke tingkat pendapatan dan pendidikan yang rendah. Penghasilan yang mereka dapatkan digunakan untuk kehidupan sehari-hari dan biaya anak sekolah. Penduduk di wilayah pesisir pantai memiliki tingkat ekonomi yang relatif rendah.

Pengawasan pembelajaran PAUD mempertimbangkan keseluruhan aspek pengembangan, bermakna, manarik, dan fungsional dikawasan pesisir. Pengawasan guru akan lebih baik jika, diperhatikan oleh pemerintah dan orang tua, dimana orangtua akan maksimal juga, jika pengawasan pemerintah dari segi peningkatan kesejahteraan guru dan masyarakat/keluarga meningkat, pembangunan pagar dan pintu pengaman sekolah misalnya guru digaji dengan tinggi oleh pemerintah, maka akan meningkatkan motivasi kerja guru yang lebih baik. Jika orang tua/keluarga/masyarakat memiliki income dan memperhatikan guru dengan baik, makatingkat pengawasan guru dalam pembelajaran dan anak PAUD akan lebih maksimal. Dari hasil pengamatan bahwa peran keluarga dalam melihat pendidikan Di Tomilito Pesisir Pantai Anggrek, di Kabupaten Gorontalo Utara sebagian besar orangtua menggangap pendidikan itu kurang penting. Seharusnya orang tua dan pemerintah harus lebih memperhatikan pendidikan.

Manajemen diperlukan dalam meningkatkan efektivitas sumber daya pendidikan anak usia dini agar menjadi efektif dan efisien, sehingga tujuan dalam pengelolaan lembaga PAUD berjalan dengan baik sehingga dapat memberikan pelayanan terbaik bagi pendidikan anak usia dini (Rohmat, 2017). Manajemen tehnik pembelajaran yang dilakukan dikawasan pesesir laut Gororntalo Utara meliputi indikator: 1) Perencanaan pembelajaran yang berpusat pada anak dikawasan pesisir hasil penelitian menjunjukkan bahwa belum sepenuhnya mendapatkan dukungan motivasi orang tua, pemerintah setempat. 2) Mengorganisir pembelajaran yang aktif dikawasan pesisir hasil penelitian menunjukkan bahwa kurangnya fasilitas sarana pembelajaran. 3) Menggerakkan pendidikan anak usia dini hasil menunjukkan bahwa belum maksimalnya peran orang tua disebabkan faktoe 
ekonomi. 4) Melalui pengalaman langsung dengan objek dikawasan pesisir, Mengawasi pembelajaran PAUD mempertimbangkan keseluruhan aspek pengembangan (bermakna, manarik, dan fungsional dikawasan pesisir) hasil menunjukkan bahwa sebagian besar orangtua menggangap pendidikan itu kurang penting.

Seharusnya orang tua dan pemerintah harus lebih memperhatikan pendidikan pada anak usia dini. Untuk itu, hendaklah guru, orang tua, masyarakat, maupun pemerintah untuk berkolaborasi dalam membangun generasi yang cerdas, karena anak yang cerdas adalah anak yang distimulasi baik dengan dukungan lingkungan yang baik juga (Ita, 2018). Pentingnya kesadaran orang tua, masyarakat, dan pemerintah dalam meningkatkan pertumbuhan dan perkembangan anak dalam pendidikan anak usia dini, karena pendidikan anak usia dini merupakan pendidikan yang paling mendasar sebagai pondasi kehidupan anak (Watini, 2019).

\section{SIMPULAN}

Manajemen Tehnik Pembelajaran Pendidikan Anak Usia Dini di Kawasan Pesisir laut, dijabarkan berdasarkan Indikator sebagai berikut: 1) Perencanaan pembelajaran yang berpusat pada anak dikawasan pesisir. 2) Mengorganisir pembelajaran yang aktif dikawasan pesisir. 3) Menggerakkan pendidikan anak usia dini, melalui pengalaman langsung dengan objek dikawasan pesisir 4) mengawasi pembelajaran PAUD mempertimbangkan keseluruhan aspek pengembangan, bermakna, manarik, dan fungsional dikawasan pesisir. Keempat indikator ini penting bagi masa depan anak usia dini di kawasan pesisir, untuk dapat di perhatikan oleh sebagian besar orangtua, yang menggangap pendidikan itu kurang penting. Seharusnya orang tua dan pemerintah harus lebih memperhatikan pendidikan, serta guru lebih optimal dalam mencerdaskan anak generasi bangsa indonesia yang berkualitas

\section{UCAPAN TERIMAKASIH}

Terimakasih peneliti ucapkan kepada pihak-pihak terkait dalam penelitian ini teruatama PAUD dikawasan pesisir laut Kabupaten Gorontalo Utara, Provinsi Gorontalo.

\section{DAFTAR PUSTAKA}

Ayuni, D., \& Setiawati, F. A. (2019). "Kebun Buah" Learning Media for Early Childhood Counting Ability Despa. Jurnal Obsesi : Jurnal Pendidikan Anak Usia Dini, 3(1), 1-9. https:// doi.org/10.31004/obsesi.v3i1.128

Barnawi, \& Adi, W. (2011). Format PAUD. Ar-Ruzzmedia.

Çalışkan, A., \& Özdemir, A. (2018). Meeting Management Skills of District Directors of National Education According to Perceptions of School Managers. Journal of Education and Training Studies, 6(11), 113-127. https://doi.org/10.11114/jets.v6i11.3200

Elya, M. H. (2020). Pengaruh Metode Bercerita dan Gaya Belajar terhadap Kemampuan Berbicara Anak Usia Dini. Jurnal Obsesi : Jurnal Pendidikan Anak Usia Dini, 4(1), 302315. https:// doi.org/10.31004/obsesi.v4i1.326

Fakhrudin, A. . (2010). Sukses Menjadi Guru TK/PAUD. Bening.

Fatimah, D. F., \& Rohmah, N. (2016). Pola Pengelolaan Pendidikan Anak Usia Dini di PAUD Ceria Gondangsari Jawa Tengah. MANAGERIA: Jurnal Manajemen Pendidikan Islam, 1(November), 247-273. https:// doi.org/ doi.org/10.14421/manageria.2016.12-05

Garzia, M., Yufiarti, Y., \& Hartati, S. (2019). Perbedaan Kesiapan Sekolah Anak Usia Dini di Daerah Pesisir Ditinjau dari Status Ekonomi Orang Tua dan Parenting. Jurnal Obsesi : Jurnal Pendidikan Anak Usia Dini, 3(2), 470-483. https:// doi.org/10.31004/obsesi.v3i2.239 
Hägglund, S., \& Samuelsson, I. P. (2009). Early childhood education and learning for sustainable development and citizenship. International Journal of Early Childhood, 41(2), 49-63. https://doi.org/10.1007/BF03168878

Hartman, S., Winsler, A., \& Manfra, L. (2017). Behavior Concerns Among Low-Income, Ethnically and Linguistically Diverse Children in Child Care: Importance for School Readiness and Kindergarten Achievement. Early Education and Development, 28(3), 255-273. https://doi.org/10.1080/10409289.2016.1222121

Ita, E. (2018). Manajemen Pembelajaran Pendidikan Anak Usia Dini di TK Rutosoro Kecamatan Golewa Kabupaten Ngada Flores Nusa Tenggara Timur. Jurnal Dimensi Pendidikan Dan Pembelajaran, 6(1), 45-52. https://doi.org/10.24269/dpp.v6i1.889

John Mc, M. (2010). Design dan Perencanaan Sistem Informasi. Luxima.

Kadir, N. J., \& Adebayo, T. A. (2019). Digitization In Education System and Management of Early Childhood Care Education in Nigeria. Southeast Asia Early Childhood Journal, $8(2), 28-42$.

Kasim, F., Nursinar, S., Panigoro, C., Karim, Z., \& Lamalango, A. (2017). Pemanfaatan dan Persepsi Masyarakat Sekitar Hutan Mangrove terhadap Kerusakan Hutan Mangrove di Pesisir Kabupaten Gorontalo Utara, Kasus Kecamatan Tomilito. Prosiding Seminar Nasional KSP2K II, 1(2), 33-44.

Masitoh, \& dkk. (2005). Strategi Pembelajaran TK. Universitas Terbuka.

Masri Amiruddin. (2017). Pendidikan Anak Nelayan Pesisir Pantai Donggala. Environment, 1(September), 223-227.

Miles, M., \& Huberman, M. (2005). No Qualitative Data Analysis (Terjemah). UI Press.

Munastiwi, E. (2019). Manajemen Ekstrakurikuler Pendidikan Anak Usia Dini (PAUD). MANAGERIA: Jurnal Manajemen Pendidikan Islam, 3(2), 369-380. https://doi.org/10.14421/manageria.2018.32-09

Nuraeni. (2014). Strategi Pembelajaran untuk Anak Usia Dini. Jurnal Pengkajian Ilmu Pembelajaran Matematika Dan IPA "Prisma Sains," 2(2), 143-153. https://doi.org/10.33394/j-ps.v2i2.1069

Patimah, R. S., \& Nurhayati, S. (2020). Manajemen Lembaga Taman Kanak-kanak Berprestasi dalam Rangka Mencetak Anak Usia Dini yang Unggul dan Berkarakter. Comm-Edu $\begin{array}{llll}\text { (Community Education 3(1), 6-17. } & \end{array}$ https://doi.org/dx.doi.org/10.22460/comm-edu.v3i1.3296

Rahman, P., \& Yusuf, E. (2012). Gambaran Pola Asuh Orangtua Pada Masyarakat Pesisir Pantai. Predicara, 1(1), 21-36.

Rohmat. (2017). Manajemen Pendidikan anak usia dini. Vin Vang, 11(2). https:/ / doi.org/DOI: 10.24090/ yinyang.v12i2.2017.pp299-325

Saripudin, A., \& Faujiah, I. Y. (2018). Strategi Edutainment dalam Pembelajaran Di PAUD ( Studi Kasus Pada TK di Kota Cirebon ). AWLADY: Jurnal Pendidikan Anak, 4(1), 129. https://doi.org/10.24235/awlady.v4i1.2637

Suryana, A. (2007). Tahap-Tahapan Kualitatif. Universitas Pendidikan Indonesia.

Tanto, O. D., Hapidin, H., \& Supena, A. (2019). Penanaman Karakter Anak Usia Dini dalam Kesenian Tradisional Tatah Sungging. Jurnal Obsesi : Jurnal Pendidikan Anak Usia Dini, 3(2), 337. https://doi.org/10.31004/obsesi.v3i2.192

Watini, S. (2019). Implementasi Model Pembelajaran Sentra pada TK Labschool STAI Bani Saleh Bekasi. Jurnal Obsesi: Jurnal Pendidikan Anak Usia Dini, 4(1), 110. https://doi.org/10.31004/obsesi.v4i1.190 